\title{
Impacts of winter cover cropping on soil moisture and evapotranspiration in California's specialty crop fields may be minimal during winter months
}

\author{
Results from a 3-year study suggest that processing tomato and almond growers can adopt winter \\ cover cropping without changing irrigation practices.
}

\begin{abstract}
by Alyssa DeVincentis, Samuel Sandoval Solis, Sloane Rice, Daniele Zaccaria, Richard Snyder, Mahesh Maskey, Anna Gomes, Amélie Gaudin and Jeffrey Mitchell
\end{abstract}

Online: https://doi.org/10.3733/ca.2022a0001

W ater usage for agricultural production has become a focus of attention among researchers, growers, policymakers and the general public as the combination of climate change and population growth threatens the availability of freshwater resources (IPCC 2014). For irrigated agriculture to be sustainable, land use decisions must consider water as a limiting factor; however, empirical data on water implications of many sustainable agricultural practices is lacking (Iglesias and Garrote 2015; Rodriguez et al. 2009). The lack of such information can lead to low adoption of sustainable agricultural practices, such as with winter cover cropping in California (Carlisle 2016).

Although winter cover crops - a wide variety of plants that includes native grasses or seed mixes of annual grasses and legumes - have emerged as a sustainable agricultural management practice, they are not yet commonly adopted in the semi-arid Western states and are grown on less than $5 \%$ of farmland in California (Soil Health Institute 2019), potentially due to uncertainties about the water required to establish and maintain a cover crop and the costs associated with cover cropping. Winter cover crops grow in the cool season between specialty crop production cycles - when the land would otherwise be left fallow - and

\section{Abstract}

As fresh water supplies become more unreliable, variable and expensive, the water-related implications of sustainable agriculture practices such as cover cropping are drawing increasing attention from California's agricultural communities. However, the adoption of winter cover cropping remains limited among specialty crop growers who face uncertainty regarding the water use of this practice. To investigate how winter cover crops affect soil water and evapotranspiration on farm fields, we studied three systems that span climatic and farming conditions in California's Central Valley: processing tomato fields with cover crop, almond orchards with cover crop, and almond orchards with native vegetation. From 2016 to 2019, we collected soil moisture data (3 years of neutron hydroprobe and gravimetric tests at 10 field sites) and evapotranspiration measurements ( 2 years at two of 10 sites) in winter cover cropped and control (clean-cultivated, bare ground) plots during winter months. Generally, there were not significant differences in soil moisture between cover cropped and control fields throughout or at the end of the winter seasons, while evapo-transpirative losses due to winter cover crops were negligible relative to clean-cultivated soil. Our results suggest that winter cover crops in the Central Valley may break even in terms of actual consumptive water use. California growers of high-value specialty crops can likely adopt winter cover cropping without altering their irrigation plans and management practices.

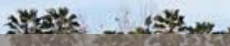

Co-authors Alyssa DeVincentis and Sloane Rice install surface renewal equipment at Davis. New UC field research indicates that growers who farm processing tomatoes and almond trees in the Central Valley can potentially benefit from soil health advantages associated with winter cover cropping without increasing their water footprint. Photo: Jose Pablo Ortiz Partida 
offer extensive soil-related benefits (e.g., soil health and erosion control) for agriculture in many climates and production systems (Delpuech and Metay 2018; Keating et al. 2010; Lu et al. 2000; Pieters and McKee 1938; Shackelford et al. 2019).

Two of the most prominent crops in California in terms of acreage, processing tomato and almond, are produced amidst a combination of pressures that affect their management decisions (California Department of Food and Agriculture 2018). Growers must manage water resources to meet the unique agronomic requirements of their crops within a highly engineered system of surface water deliveries, while complying with environmental regulations, and under a changing climate that is creating increasingly variable, more expensive and often unreliable water supplies (Aguilera et al. 2013; Hanak et al. 2019; Pathak et al. 2018). To compound the situation, major institutions responsible for designing and implementing agricultural management policies, such as government agencies that manage water or promote land conservation, may push farmer priorities in opposing directions if their recommendations are not in agreement with each other.

Previous research suggests that cover crops may cause increased soil moisture depletion and calls for a more comprehensive analysis of the impacts of winter cover cropping on soil moisture and evapotranspiration in California's specialty crop industries (Mitchell et al. 2015; Mitchell et al. 2008). However, past research is often dated or has been conducted in temperate regions of the United States not facing similar agricultural challenges as California (McVay et al. 1989; Prichard et al. 1989). While growers anticipate benefits from winter cover cropping, they lack concrete information to decide if the potential water footprint is worth the operational costs and potential hurdles associated with this practice (DeVincentis et al. 2020; Sarrantonio and Gallandt 2003).

As a result of recurrent drought conditions in California, there is a need to quantify how winter cover

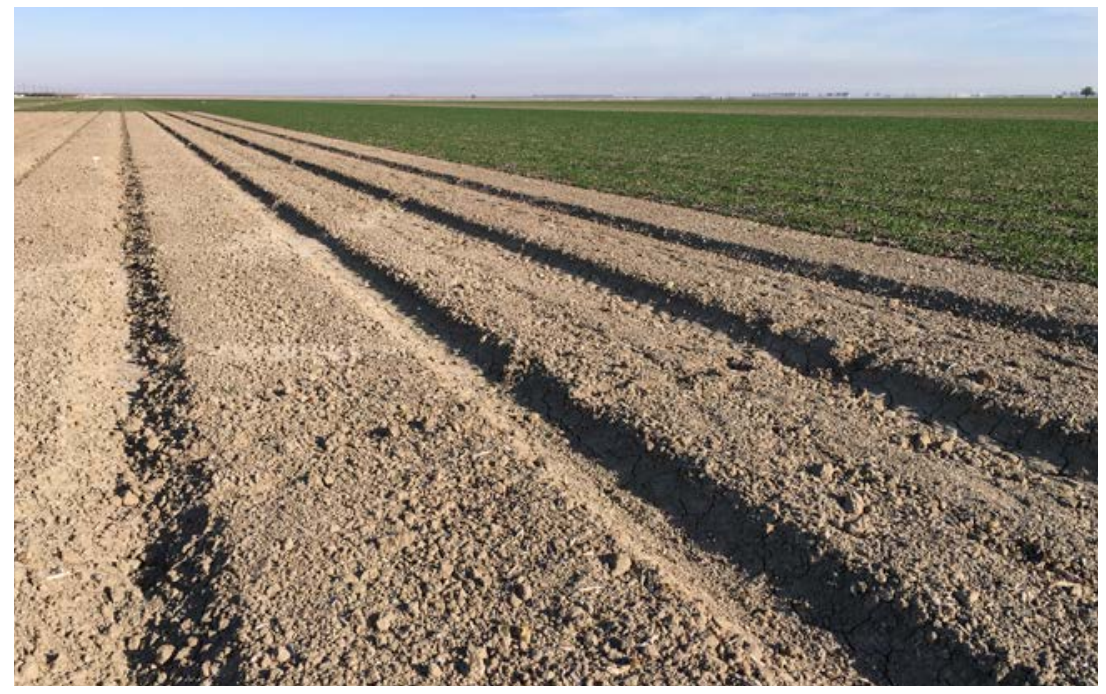

Cover crop and control side by side in Firebaugh. Photo: Jeffrey Mitchell cropping affects soil moisture and evapotranspiration on agricultural production fields across specialty cropping systems and climate gradients in California. This is a critical step in understanding the water-related implications of winter cover cropping and barriers to adoption of this sustainable farming practice in semiarid irrigated systems. Our findings have implications for growers, water resource planners and managers, and policy makers working at the interface of agricultural production and resource conservation in the water-limited context of California and other western U.S. states.

\section{Quantifying water budget components}

Winter cover crops may affect the water budget on farms in the short-term through improved infiltration and rainfall capture, soil erosion control, changes in actual evapotranspiration losses, dew capture, and soil cooling; or in the long-term through increased organic matter content that improves soil-water dynamics (Basche et al. 2016; Lu et al. 2000; Tautges et al. 2019; Ward et al. 2012). Our goal was to assess how winter cover crops affect two of these components, i.e., soil moisture and field evapotranspiration, during the period from late fall to early spring on irrigated tomato and almond production fields in California's Central Valley. To quantify these parameters, we established comparative plots of winter cover crops and bare ground (clean-cultivated soil), serving as control, in the two crop systems across California's broad climate gradient. Study sites were located in the northern Central Valley near Chico, an area that has an average annual precipitation of 30 inches, and the southern San Joaquin Valley, where precipitation is about 5 inches per year. Our research team first analyzed the soil water content using soil moisture measurements, and then determined water losses due to actual evapotranspiration $\left(\mathrm{ET}_{\mathrm{a}}\right)$ using the residual of the energy balance (REB) method on a subset of fields (fig. 1). The resulting data sets were then analyzed and interpreted to estimate the impacts on soil water content and water losses by comparing cover cropped and control plots at each study site.

\section{Experimental design}

The study was conducted over a 3-year field campaign on commercial production farms and research sites throughout the Central Valley from 2016 to 2019. We established 10 field sites through partnerships with eight commercial farms (in Orland, Chico, Durham, Dixon, Merced, Firebaugh, Shafter and Arvin) and two experimental facilities located at University of California Agricultural Experimental Stations (Davis and Five Points) to represent the diversity of tomato and almond operations within the Central Valley (fig. 2). Variables differing among sites included annual precipitation, average temperature, past use of winter cover crops, soil type and management history, and 


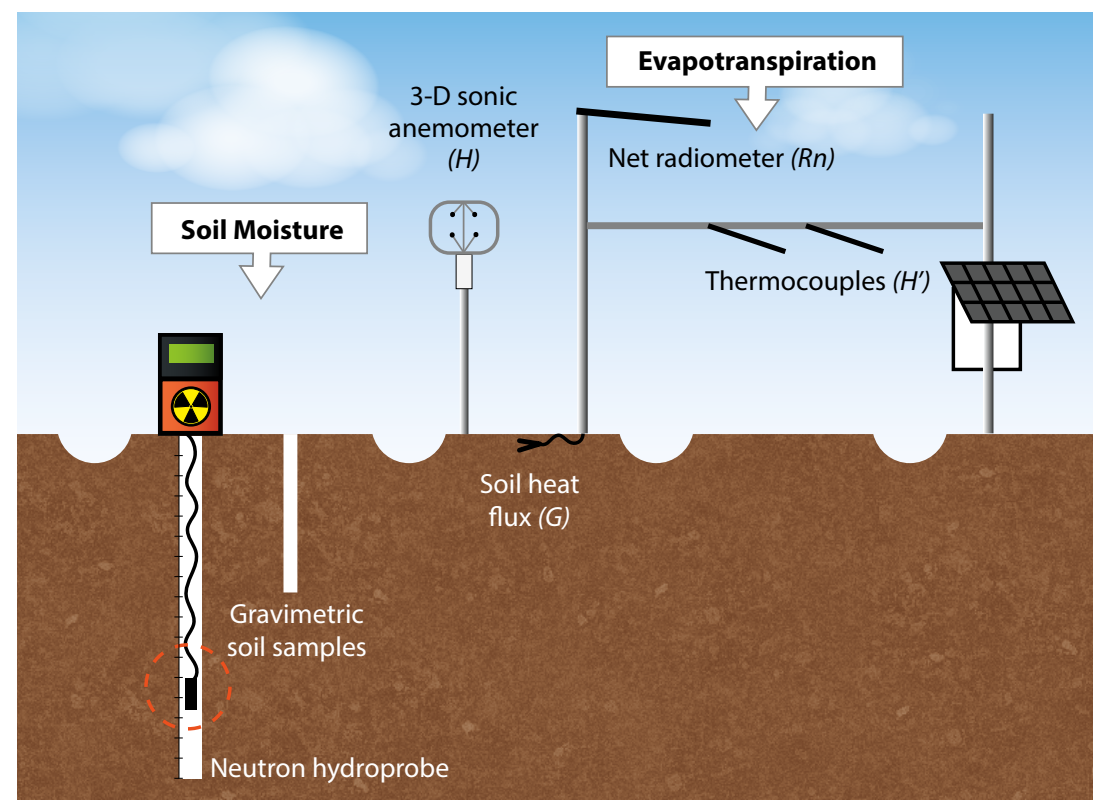

FIG. 1. Schematic of data collection on winter cover cropped and control (bare ground) fields. Illustration: Larken Root.

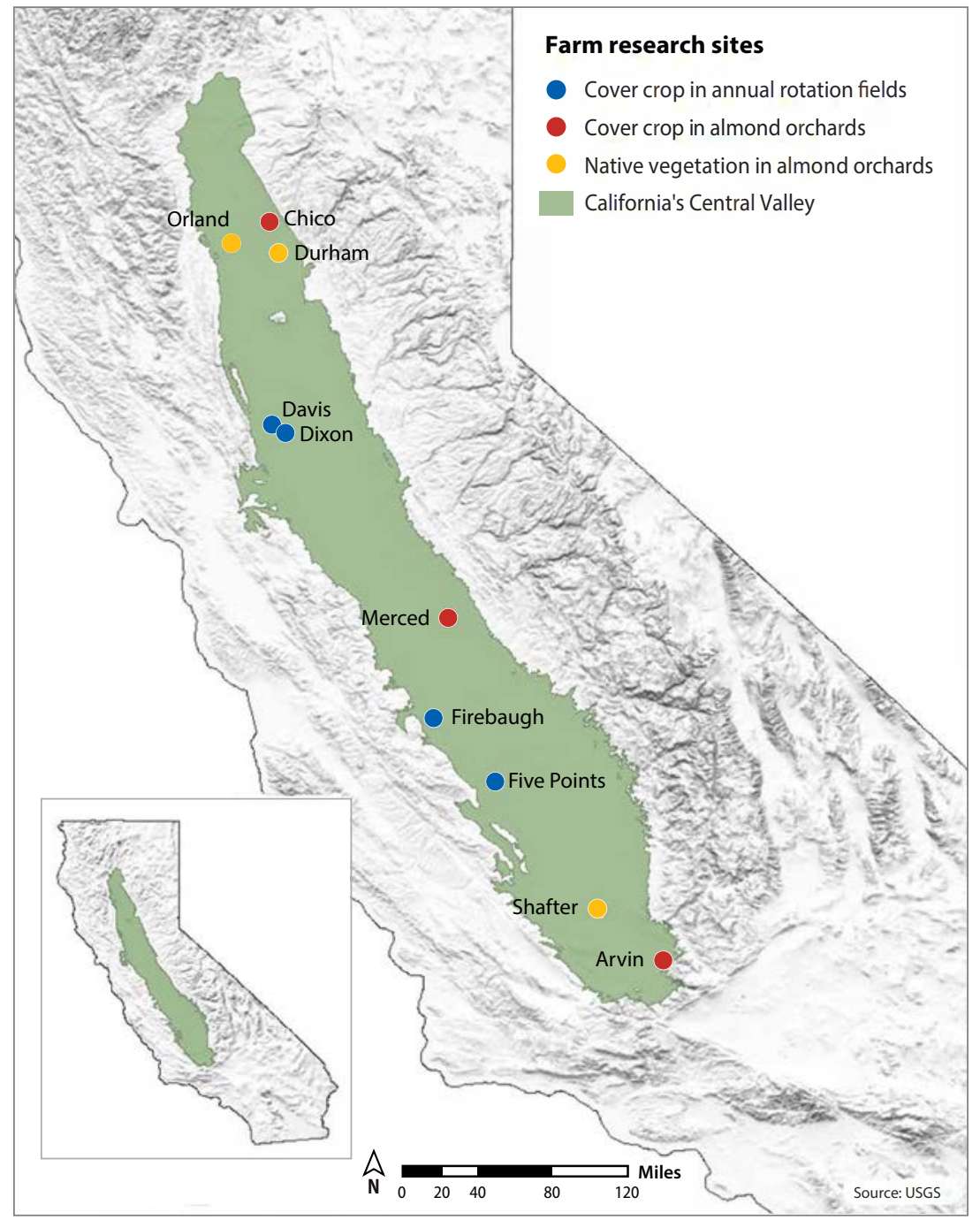

FIG. 2. Map of data collection sites at eight commercial production farms and two University of California research farms. Source: USGS. whether it was an annual (tomato) or perennial (almond) cropping system.

To represent the distinct priorities and management preferences between processing tomato and almond orchard systems, we selected sites that manage three types of winter cover crop systems: (1) cover crop (usually a mix of peas and oats) planted in fields where processing tomatoes are grown in rotation with other annual crops, referred hereafter to as annual rotation fields, (2) cover crop planted in the tree inter-rows of almond orchards and (3) native vegetation (grasses) allowed to grow in tree inter-rows in almond orchards, which represents the simplest orchard floor management practice.

A replicable experimental design was implemented at each study site while working within the grower's capacity and means to accommodate the data collection process. On-farm experimental design included a cover cropped area to be compared with a control area (clean-cultivated) of at least 4 acres in the annual rotation fields, and at least four rows in the almond orchards (table S1 in the online technical appendix). Vegetative growth in the control areas was suppressed with herbicide application once in the fall at most sites.

\section{Data collection}

The soil moisture data collection process generally started in late fall for all sites (as early as October) and continued until early spring (as late as March) for the annual rotation fields and early summer (as late as June) for almond orchards from 2016 to 2019. We used a neutron hydroprobe (Campbell Pacific Nuclear, Martinez, Calif.) to measure seasonal changes in soil moisture between winter cover cropped and control plots at all sites with replications in time to varying degrees. A minimum of four neutron hydroprobe access tubes were installed in each treatment area at each study site to enable soil moisture readings between 0.15 meter $[\mathrm{m}]$ below the soil surface and $2.7 \mathrm{~m}$ deep at 0.30 - $\mathrm{m}$ increments if site conditions permitted. Soil samples were taken during the installation of the access tubes and sporadically throughout the field campaign (Grismer et al. 1995). Analytical determinations of the gravimetric water content were conducted on 2,755 soil samples to validate results from the neutron hydroprobe readings.

The $\mathrm{ET}_{\mathrm{a}}$ of the winter cover cropped and control plots was determined for two sites (Davis and Five Points) for a period across 2017-2018 with the REB method using the surface renewal (SR) technique and equipment. The REB method calculates the latent heat flux (LE) as the residual of the surface energy balance, which is then used to determine $\mathrm{ET}_{\mathrm{a}}$. Further information on the methodology and equipment used to collect data on changes in soil moisture and evapotranspiration are provided in the online technical appendix. 


\section{Data processing}

The substantial set of experimental data provided an opportunity to estimate the effects of cover cropping on soil moisture and $\mathrm{ET}_{\mathrm{a}}$ despite its inconsistencies in time and space, which were due to the inherent challenges faced in a field research study covering a large geographic area and involving dozens of on- and off-farm collaborators.

Analyzing soil moisture. We analyzed (1) statistical differences between soil moisture for each individual day and depth of data collection, (2) trends in a study site's soil moisture ratio and (3) trends in the change of fractional soil moisture over the winter season for each winter cover cropping system.

Data sets were first analyzed to determine the percent of time and depth along the soil profile when soil moisture content differed between winter cover crop and control plots at each study site. This was done using two measurement methods: neutron hydroprobe and gravimetric soil moisture. A series of $t$-tests were conducted using R software package (version 3.6.0; R Foundation for Statistical Computing, Vienna, Austria) to evaluate the significance of the treatment factor (i.e., winter cover crop versus control) on soil moisture using all measurements collected on a given day and at a given depth for a particular site. We conducted a total of 3,755 tests from the neutron hydroprobe and 323 tests from gravimetric soil determination of soil samples.

Based on the results of our analysis, the neutron hydroprobe data was used to analyze trends in soil moisture over time. Neutron hydroprobe counts were first aggregated by study site, day, depth and treatment. The counts were used to calculate soil moisture ratios by dividing the average neutron hydropobe count from each depth of the winter cover cropped plot by the average count from the corresponding control plot. A soil moisture ratio greater than 1 indicated relatively more water in the cover cropped plot compared to the control.

Then, fractional soil moisture was calculated for the top $1.2 \mathrm{~m}$ of the soil profile to identify trends in cover crop systems. To calculate fractional soil moisture at each site and each day of data collection, we normalized the average neutron hydroprobe count by the maximum soil moisture measured at the corresponding treatment, site and season. The maximum soil moisture was determined separately for each treatment to account for potential differences in soil hydraulic properties between the individual plots. This process identified a point of relative saturation, i.e., the day when soil in each treatment plot reached its maximum moisture content and allowed us to see how the soil moisture content in each treatment changed over the season. The resulting data set of fractional soil moisture was used to compare the percentage of peak soil moisture retained by cover cropped and control plots at the end of the winter season, providing a method to identify trends in a heterogeneous data set.

Analyzing evapotranspiration. Data sets of the surface energy balance parameters collected using micro-meteorological measurements were analyzed and the REB method was used to quantify the actual water losses $\left(\mathrm{ET}_{\mathrm{a}}\right)$ in winter cover cropped and control plots. We compiled and used three data types for the analyses: weather, preflux and energy balance data (Paw U et al. 1995; Snyder et al. 1996). Further information on the methodology used to quantify the $\mathrm{ET}_{\mathrm{a}}$ is provided in the technical appendix. Additional information on the SR and sonic anemometer analysis used in this research are fully discussed by Shapland et al. (2012).

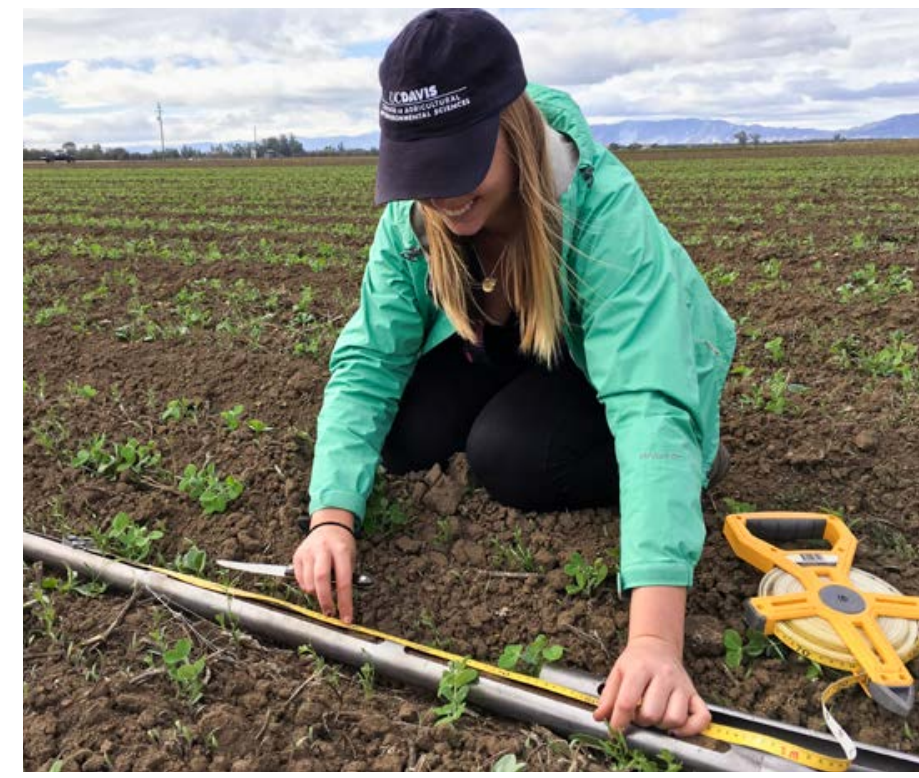

Co-author Alyssa DeVincentis taking baseline soil samples in Davis in 2016. Photo: Sloane Rice

To compare $\mathrm{ET}_{\mathrm{a}}$ of cover crop and control fields with reference grass surface, reference evapotranspiration $\left(\mathrm{ET}_{\mathrm{o}}\right)$ values were obtained from the nearest weather stations of the California Irrigation Management Information System network (https://cimis.water. ca.gov/): number 6 (Davis) and number 2 (Five Points).

\section{Soil moisture}

Soil moisture was generally not statistically different $(P$-value $<0.05)$ between cover cropped and control plots at individual sites during the winter season (table 1, fig. 3). Of the 3,785 unique depth-day combinations from the neutron hydroprobe data set, 520 (14\%) were statistically different; of the 337 unique combinations from the gravimetric soil water content data set, 39 (12\%) were statistically different. The trend of minimal difference in soil moisture from the neutron hydroprobe data set was confirmed with results from the gravimetric soil moisture determination (fig. 3); therefore, the remainder of analyses were based on the neutron hydroprobe data set, which is more extensive and detailed in time and space.

We found different patterns of soil moisture trends for each cover cropping system (fig. 3). Annual rotation fields with a winter cover crop showed the widest range of soil moisture, with percentage of time when soil water content differed ranging from $2 \%$ to $29 \%$ with respect to control plots. This high variability may be a function of the specific management history on each field, which differed among the four annual rotation field sites, as well as the soil- and crop-specific impacts on soil moisture and evapotranspiration of winter cover cropping. Almond orchards with winter cover crop showed a more consistent behavior, possibly because almonds are grown on a narrower range of soils than processing tomatoes in California with low to no soil disturbances. The soil moisture at these almond sites was not statistically different $(P$-value $<0.05)$ between the winter cover cropped area and the control over $95 \%$ of the time. These sites had the fewest depth-date combinations to analyze (959) and did not grow winter cover crops before the present experiment. Almond orchards that allowed growing native vegetation as a winter cover crop showed differences in soil 
TABLE 1. Summary of neutron hydroprobe data collected from 10 Central Valley research sites, 2016 to 2019

\begin{tabular}{|c|c|c|c|c|c|}
\hline \multirow[b]{2}{*}{ Site location } & \multirow[b]{2}{*}{ Latitude } & \multirow{2}{*}{$\begin{array}{l}\text { No. days of data } \\
\text { collection }\end{array}$} & \multirow{2}{*}{$\begin{array}{l}\text { No. depth-date } \\
\text { combinations used } \\
\text { in analysis }\end{array}$} & \multicolumn{2}{|c|}{$\begin{array}{l}\text { Percentage of depth-dates combinations with } \\
\text { more water in each treatment }\end{array}$} \\
\hline & & & & Winter cover crop & Control \\
\hline \multicolumn{6}{|c|}{ Cover crop in annual rotation fields } \\
\hline Davis & 38.55 & 47 & 423 & 0.2 & 2.1 \\
\hline Dixon & 38.51 & 32 & 288 & 2.8 & 4.2 \\
\hline Five Points & 36.34 & 41 & 342 & 3.2 & 25.4 \\
\hline \multicolumn{6}{|c|}{ Cover crop in almond orchards } \\
\hline Chico & 39.8 & 29 & 199 & 0.0 & 3.0 \\
\hline Merced & 37.37 & 45 & 450 & 0.9 & 2.0 \\
\hline Durham & 39.61 & 60 & 553 & 0.7 & 27.8 \\
\hline Shafter & 35.53 & 50 & 463 & 6.9 & 15.1 \\
\hline Average of all sites & & & & 3.7 & 9.3 \\
\hline
\end{tabular}

Neutron probe

Gravimetric water content

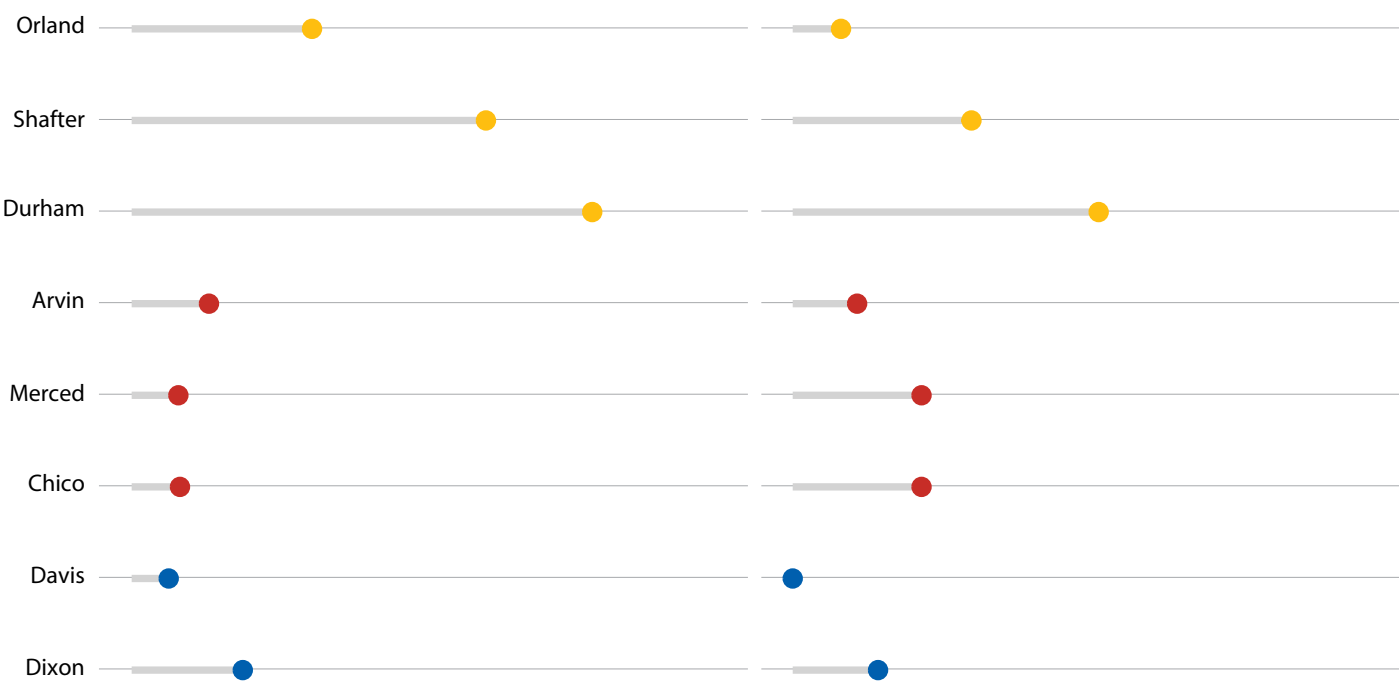

Firebaugh

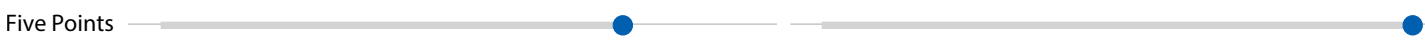

\begin{tabular}{|c|c|c|c|c|c|c|c|}
\hline 1 & 10 & 20 & 30 & 0 & 10 & 20 & $\begin{array}{l}7 \\
30\end{array}$ \\
\hline
\end{tabular}

Percent of time soil moisture differs between treatments (\%)

FIG. 3. Percent of observations (depth-date combinations) when soil moisture differs between treatments (winter cover cropped and control plots, $P$-value $<0.05)$. Values are based on all available data for each site over the entire time period of data collection from 2016 to 2019. 
moisture with a slightly higher frequency, i.e., an average of $20 \%$ of the time.

In this study, rootzone depths for cover crops vary due to the different types of cover crops grown. Despite this variation, there are interesting trends in the instances where soil moisture differed between winter cover cropped and control plots. Difference in soil moisture occurred most often in the cover crop active uptake water zone between $0 \mathrm{~cm}$ and $120 \mathrm{~cm}$, averaging $83 \%$ across the study sites (table 2). Future studies may only need to look at this part of the soil profile to further investigate the soil moisture and evapotranspiration impacts of winter cover crops over time.

For almond orchards, the instances when soil moisture differed reveal contrasts between the use of winter cover crop and native vegetation. Orchard plots with winter cover crop show infrequent differences relative to the control plots (fig. 3). These sites had not used winter cover crop before the present study and may provide insight into what growers can expect during the transitional period when a farm starts implementing this practice. When native vegetation was used as a winter cover in almond orchards, the soil moisture in the control area is often greater. During the data collection campaign, we noticed that during intense winter precipitation events, water pooled on the surface of those orchard rows in control plots more than in cover cropped plots. Pooled water creates unfit farming conditions that could prevent or complicate the use of machinery or trigger the occurrence of anaerobic conditions in almond orchards during the winter. The presence of a winter cover may be reducing compaction and improving infiltration, facilitating vertical and lateral water movement.

TABLE 2. Summary of instances when soil moisture differs between winter cover crop and control (bare ground) agricultural fields in California's Central Valley

\begin{tabular}{|l|c|c|}
\hline Winter cover crop system & $\begin{array}{c}\text { Percentage of depth-dates where soil moisture differs } \\
\text { between treatments }\end{array}$ & \begin{tabular}{l}
$121-270 \mathrm{~cm}$ \\
\hline Cover crop in annual rotation fields
\end{tabular} \\
\hline Cover crop in almond orchards & 93 & 7 \\
\hline Native vegetation in almond orchards & 85 & 15 \\
\hline Average of all sites & 78 & 22 \\
\hline
\end{tabular}

FIG. 4. Ratio of soil moisture content at four study sites based on all available data for each site over the entire time period of data collection for the first two seasons (fall 2016 to spring 2017 and fall 2017 to spring 2018). A ratio greater than one indicates relatively more water in the cover cropped plot compared to the control.

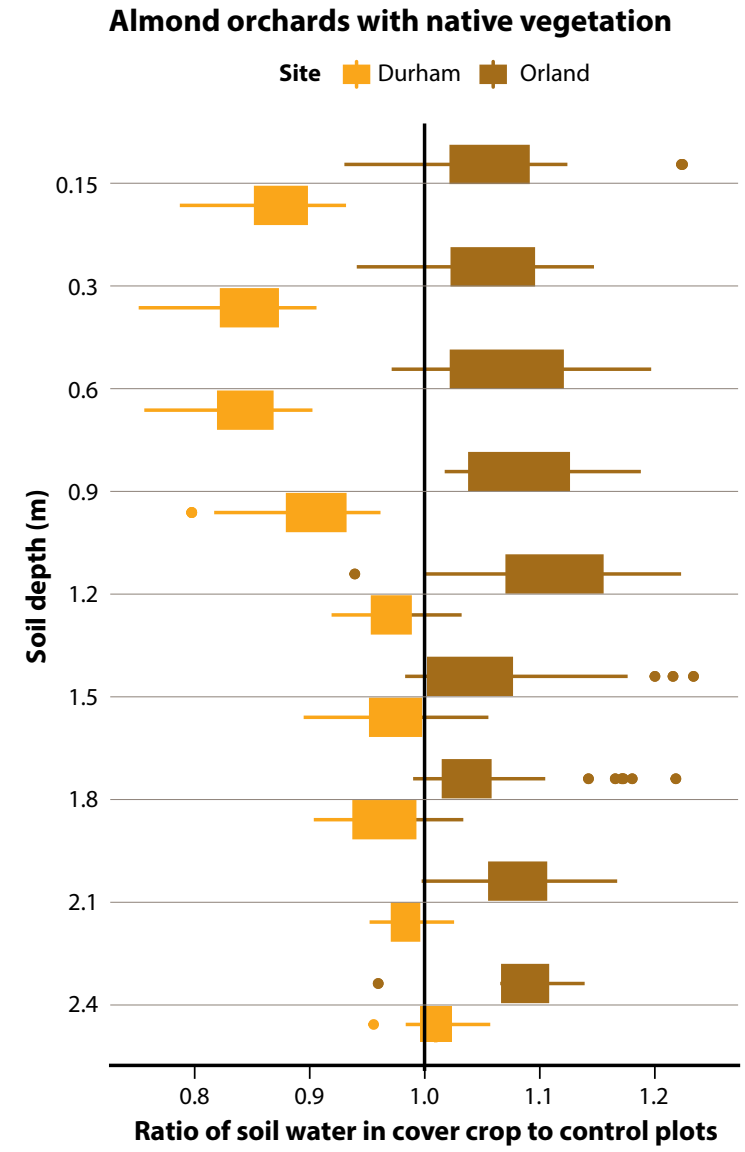

Annual rotation fields with winter cover crop

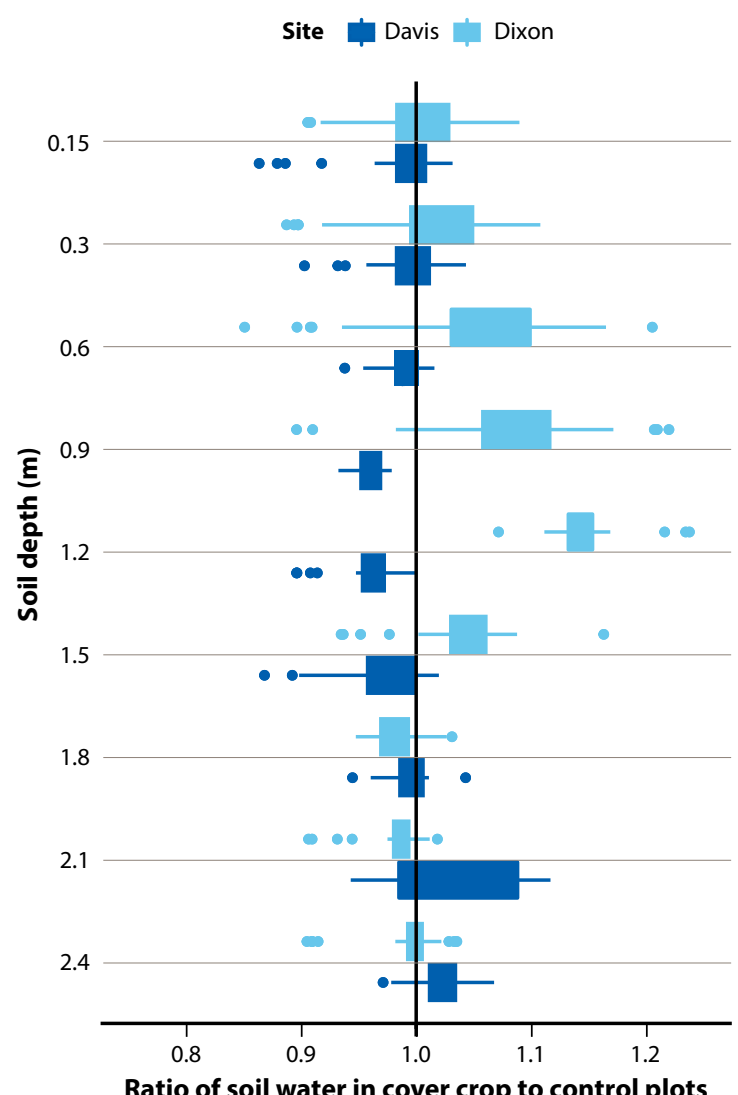




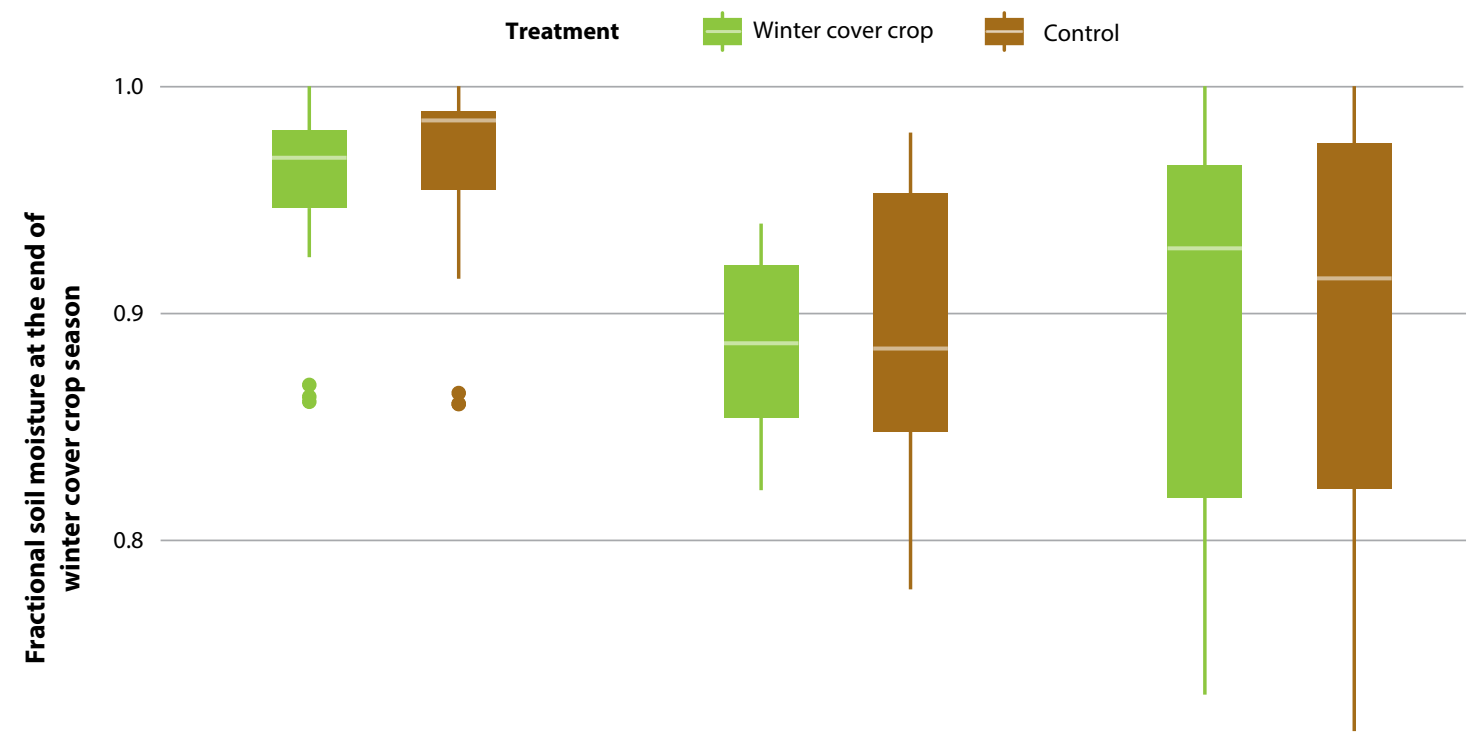

0.7

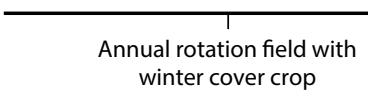

Almond orchard with winter cover crop

Almond orchard with native vegetation

FIG. 5. Box plots of fractional soil moisture averaged across $1.2 \mathrm{~m}$ at the end of the winter cover crop season offer a comparison of the percentage of peak soil moisture retained by cover cropped and control plots in annual rotation fields and almond orchards.
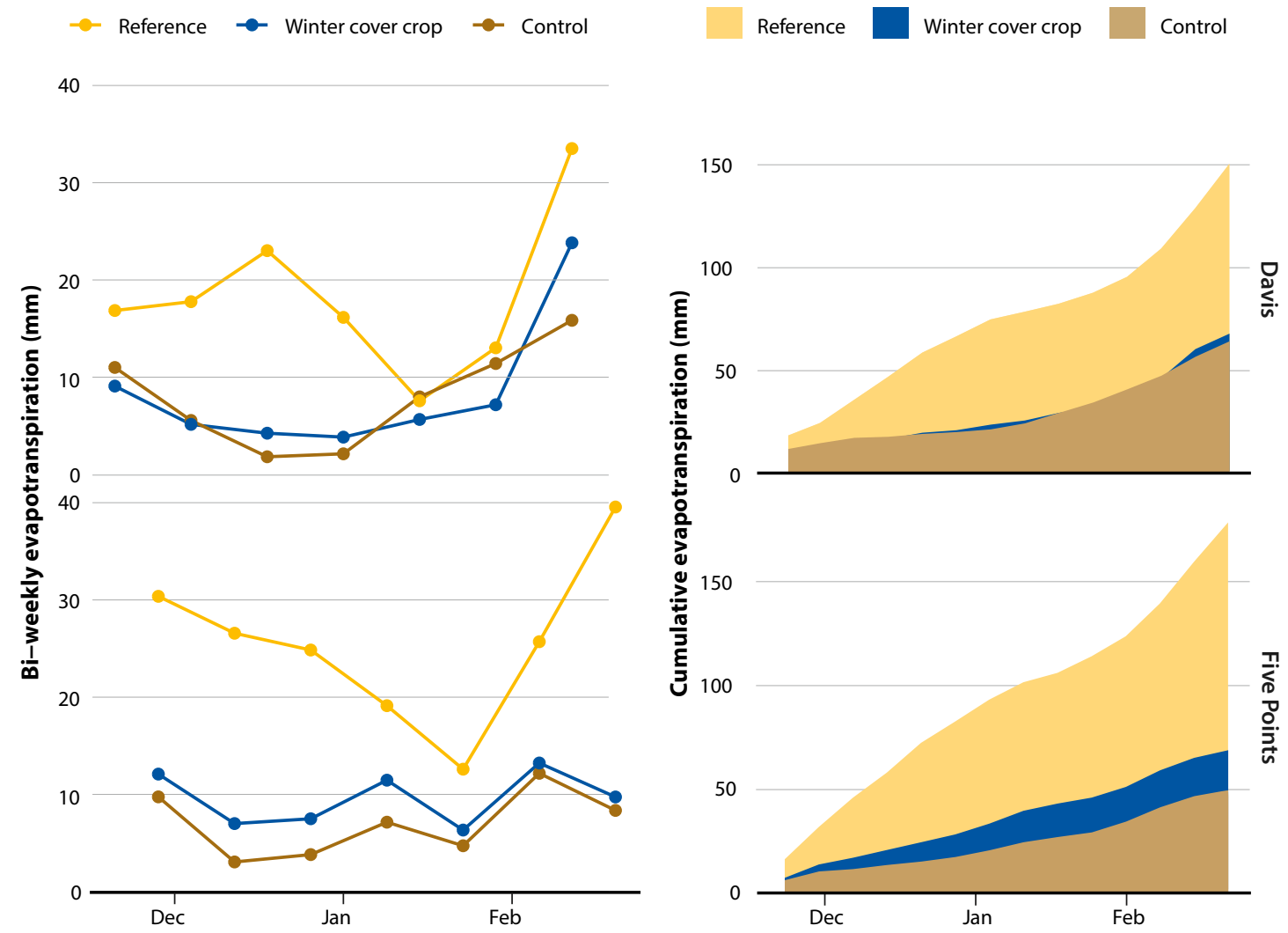

FIG. 6. Bi-weekly and cumulative actual evapotranspiration $\left(E T_{a}\right)$ for winter cover cropped and control (bare ground) plots on annual rotation fields and reference evapotranspiration (ETo). Data was collected during the winter cover crop season of November 2017 to February 2018. 
A closer look at the individual sites within a single cover crop system reveal important differences between sites that are similar in cover cropping practice, location and precipitation patterns. The aggregated soil moisture ratios for seasons 1 and 2 show that winter cover crops or native vegetation can impact soil moisture on neighboring production fields in different ways (fig. 4). Examining sites with similar pedoclimatic conditions shows significant differences based on vegetative growth and diversity of cover crop mix. For instance, in the almond orchards the plots with thicker vegetation showed a lower ratio (i.e., more water in the control plot), while in the tomato fields the plots with a mixture of over a dozen cover crop seed species showed a higher ratio (i.e., more water in the cover crop plot) than the plots with a three-seed mix (technical appendix).

Given the differences between study sites, in particular sites in similar climates and soils as previously discussed, there are not significant differences in soil moisture at the end of the winter season when results from all seasons and sites are aggregated (fig. 5). On average, the production fields in this study never lost more than $15 \%$ of fractional soil moisture from peak soil moisture by the end of the winter cover crop season, for either winter cover crop or control treatments. This result reveals that soil moisture retention was not observably different between treatments in aggregate.

\section{Evapotranspiration}

Our research team measured $\mathrm{ET}_{\mathrm{a}}$ over the course of two winter cover crop seasons from 2016 to 2018 . The measurements conducted during the first year of data collection provided a proof of concept for monitoring $\mathrm{ET}_{\mathrm{a}}$ over a winter cover crop and allowed the research team to refine the data collection protocols and data management system. We report $\mathrm{ET}_{\mathrm{a}}$ values determined from the data collection period of the second year (November 2017 to February 2018), where a ten-fold difference in precipitation between the two sites, Davis (125 millimeters [mm]) and Five Points (12 mm), allow for a climatic comparison from November 15, 2017, to February 20, 2018.

The difference in seasonal cumulative $\mathrm{ET}_{\mathrm{a}}$ between winter cover cropped and control ground is negligible in both Davis $(3 \mathrm{~mm})$ and Five Points $\left(18 \mathrm{~mm}\right.$ ) (fig. 6). The cumulative $\mathrm{ET}_{\mathrm{a}}$ in Five Points is greater than the amount of precipitation in the same time period, but may have been fed by preceding rainfall and some stored soil moisture, and these differences in evapo-transpirative water use can be considered insignificant in the scheme of annual water requirements for processing tomatoes, which are between $450 \mathrm{~mm}$ and $500 \mathrm{~mm}$.

The bi-weekly cumulative $\mathrm{ET}_{\mathrm{a}}$ values in Davis reveal that during periods of abundant precipitation, such as in January 2018, consumptive water losses are actually greater in the control plot and are mainly due to soil evaporation from bare ground. During wet years, it would be advantageous to have a winter cover crop to slightly reduce evapo-transpirative water losses from the top soil layers. In the drier climate in Five Points, the bi-weekly $\mathrm{ET}_{\mathrm{a}}$ from the winter cover crop was always slightly higher than the control; however, this measured $\mathrm{ET}_{\mathrm{a}}$ may also include condensed moisture that the cover crop captured from dew and fog and the cumulative water losses are minimal overall.

\section{Applications and limitations}

The findings from this study may be useful for specialty crop growers in the Central Valley for several reasons. Growers with annual fields in rotation with processing tomatoes may experience a variety of changes in soil moisture resulting from winter cover cropping depending on their unique characteristics, such as soil type or management history. Their fields may experience some extra consumptive water losses through evapotranspiration during dry winters, but the water used by winter cover crops amounts to less than a single irrigation event ( $1 \mathrm{inch}$ ) and less than $10 \%$ of field $\mathrm{ET}_{\mathrm{o}}$. This small cost may be offset by the possibilities of increased soil moisture, increased organic matter content, reduced erosion and nutrient losses, and improved soil health after cover cropping for multiple years, which this study did not capture.

Additionally, cover crops can improve the effectiveness of applying water during the dormant season to refill the soil profile and leach salts. These combined potential management implications could incentivize winter cover cropping for specialty growers of annual crops that are concerned with late winter rains delaying cover crop termination, thereby preventing complications with contractual obligations (DeVincentis et al. 2020).

Almond sites showed slightly more frequent differences in soil moisture due to winter cover, but the inter-row cover and almond trees mostly occupy different spatial niches. Growers with young almond orchards (fewer than 3 years old, before they produce almonds) can take advantage of the soil health benefits of winter cover crops while their orchards are not yet producing almonds without experiencing any changes in soil moisture due to winter cover cropping. Growers with almond orchards who lease their farmland can allow native vegetation to grow as a winter cover crop to enhance their rhizosphere ecology without incurring costs that may impact their business schemes. However, it is important to note that timing of winter cover crop termination is key to having these benefits realized, avoiding delays in normal farming operations, and preventing soil moisture depletion due to extra ET when the temperature increases.

Because the research sites included commercial production fields, these findings are representative of the reality that farmers experience in California. However, our study is limited by the inherent challenges of field-based agricultural research. There are limitations to the extent of control in the experimental design when conducting research on commercial farms. Additionally, our sites differed in management history, years of cover cropping, motivations for growing cover crops, operational resources, type of cover cropping, location, rainfall, timing of cover crop termination, and soil characteristics, just to name a few variables. Despite these limitations, however, collecting data at each of these sites allowed researchers to create a diversified data set with thousands of measurements and to design a careful data analysis process.

The aforementioned limitations can be addressed in future studies that will benefit from the analytical results obtained and the lessons learned during our field research. Future research efforts aiming to better understand soil moisture changes that result from winter cover cropping could target only soil depth up to $1 \mathrm{~m}$ (estimated maximum active rootzone for cover crops), and at the same time increase the frequency of data collection, including before and after rain events. Such research should look into the rain response impacts of winter cover crops that could be captured with in-situ soil moisture sensors, which do not require the regular site visits that are necessary when using neutron hydroprobes.

Future research efforts to monitor how winter cover crops affect actual field ET are necessary to build on the initial conclusions drawn in this paper. The ET data presented here is limited in its scope of 
annual rotation fields for 2 years, and future work should aim to (1) produce longer time series of data up to and including the summer months and (2) quantify the impacts of different cover crop types and practices. However, to our knowledge, the data we presented in this article is the first of this kind in California and can act as a valuable starting point to build upon with additional and complementary data sets and analyses.

Given the combined agronomic, hydrologic, regulatory and climatic pressures facing California specialty crop growers, there is a need to identify sustainable agricultural practices that reduce the environmental impacts of farming without complicating other farm management choices. The results from our study suggest that growers can potentially benefit from soil health advantages associated with winter cover cropping with minimal water use by cover crops and without having to change their spring-summer irrigation plans and water management decisions. CA

A. DeVincentis is Director of Science \& Technology, Vitidore, Inc., and previously was Ph.D. Candidate, UC Davis; S. Sandoval Solis is Associate Professor and UC Cooperative Extension (UCCE) Specialist, Department of Land, Air and Water Resources, UC Davis; S. Rice is Business Operations Manager, Vitidore, InC., and previously was Junior Specialist, UC Davis; D. Zaccaria is Associate Professor in Agricultural Water Management for UC Cooperative Extension, Department of Land, Air and Water Resources, UC Davis; R Snyder is Biometeorology Specialist, Emeritus, UC Davis; M. Maskey is Postdoctoral Scholar, UC Merced; A. Gomes is Ph.D. Student, Stanford University, and previously was Undergraduate Student, UC Davis; A. Gaudin is Associate Professor, Department of Plant Sciences, UC Davis; J. Mitchell is UCCE Cropping Systems Specialist, Department of Plant Sciences, UC Davis.

This research was funded by a California Department of Food and Agriculture Specialty Crop Block Grant (grant agreement number 15037), the Climate Change, Water, and Society IGERT at UC Davis (NSF DGE 1069333), and the Almond Board of California (grant 19-STEWCROP7-Gaudin). This research was made possible thanks to the cooperation and dedication of our partner farmers: Rory Crowley, Nicolaus Nut Co., Chico, Calif;; Dax Kimmelshue and Candace Gallion, Kimmelshue Orchards, Durham, Calif;: Brian Bly, Hart Nut Co., Orland, Calif:; Rich Collins, The Collins Farm, Davis, Calif;; Israel Herrera, LTRAS Project, Davis, Calif.; Greg Wegis, Wegis and Young, Bakersfield, Calif.; Alan Sano and Jesse Sanchez, Sano Farms, Firebaugh, Calif.; John Bender, Bender Orchards, Shafter, Calif;; Jeff Bergeron, Castle Farms, Merced, Calif;; Merph Solorio, UC Field Station, Five Points, Calif. Thank you to Cynthia Creze, Eric Kent, Cayle Little, Octavio Lagos and José Pablo Ortiz Partida for their assistance with field trials and instrumentation. Thank you to Daniel Munk and Khaled Bali for their guidance with experimental design. Thank you to Lara Ibrahim and Holly Williams for assistance with digitizing data. Thank you to Anil Shrestha, Majdi Abou Najm and Hervé Guillon for guidance on statistical analysis. Thank you to Ellen Bruno for providing thoughtful reviews on an earlier version of this manuscript.

\section{References}

Aguilera E, Lassaletta L, Gattinger A, Gimeno BS. 2013. Managing soil carbon for climate change mitigation and adaptation in Mediterranean cropping systems: A meta-analysis. Agr Ecosyst Environ 168:25-36. https://doi.org/10.1016/j. agee.2013.02.003

Allen RG, Pereira LS, Raes D, Smith M. 1998. Crop Evapotranspiration - Guidelines for Computing Crop Water Requirements. FAO irrigation and drainage paper 56. Rome: Food and Agriculture Organization of the United Nations. www.fao.org/ docrep/X0490E/X0490E00.htm

Basche AD, Kaspar TC, Archontoulis SV, et al. 2016. Soil water improvements with the long-term use of a winter rye cover crop." Agr Water Manage 172:40-50. https://doi.org/10.1016/j.agwat.2016.04.006

[CDFA] California Department of Food and Agriculture. 2018 California Agricultural Statistics Review 2017-2018. www.cdfa. ca.gov/statistics/PDFs/201718AgReport.pdf

Carlisle L. 2016. Factors influencing farmer adoption of soil health practices in the United States: A narrative review. Agroecol Sust Food Syst 40(6):583613. https://doi.org/10.1080/21 683565.2016.1156596
DeVincentis AJ, Sandoval Solis S, Bruno EM, et al. 2020. Using cost-benefit analysis to understand adoption of winter cover cropping in California's specialty crop systems. J Environ Manage 261:110205. https://doi.org/10.1016/j.jenvman.2020.110205

Delpuech X, Metay A. 2018. Adapting cover crop soil coverage to soil depth to limit competition for water in a Mediterranean vineyard. Eur J Agron 97: 60-9. https://dol. org/10.1016/j.eja.2018.04.013

Grismer ME, Bali KM, Robinson FE. 1995. Field-scale neutron probe calibration and variance analysis for clay soil. J Irrig Drain E-Asce 121(5):354-62. https:// doi.org/10.1061/(Asce)07339437(1995)121:5(354)

Hanak E, Escriva-Bou A, Gray B, et al. 2019. Water and the Future of the San Joaquin Valley. February 2019. San Francisco: Public Policy Institute of California. www.ppic.org/publication/ water-and-the-future-of-thesan-joaquin-valley/

Iglesias A, Garrote L. 2015. Adaptation strategies for agricultural water management under climate change in Europe. Agr Water Manage 155:113-24. https://doi.org/10.1016/j.agwat.2015.03.014
[IPCC] Intergovernmental Pane on Climate Change. 2014. Climate change 2014: synthesis report. Contribution of Working Groups I, II and III to the fifth assessment report of the Intergovernmental Panel on Climate Change. Cambridge, United Kingdom: Cambridge University Press.

Keating BA, Carberry PS, Bindraban PS, et al. 2010. "Eco-efficient agriculture: concepts, challenges, and opportunities." Crop Sci 50(Mar/Apr 2010):S109-19. https://doi.org/10.2135/cropsci2009.10.0594

Lu YC, Watkins KB, Teasdale JR, Abdul-Baki AA. 2000. Cover crops in sustainable food production. Food Rev Int 16(2):12157. https://doi.org/10.1081/ Fri-100100285

McVay KA, Radcliffe DE, Hargrove WL. 1989. Winter legume effects on soil properties and nitrogen fertilizer requirements. Soil Sci Soc Am J 53(6):1856-62. Mitchell JP, Shrestha A, Irmak S. 2015. Trade-offs between winter cover crop production and soil water depletion in the San Joaquin Valley, California. J Soil Water Conserv 70(6):430-40. https://doi.org/10.2489/

jswc.70.6.430

Mitchell JP, Peters DW, Shennan C. 2008. Changes in soil water sotrage in winter fallowed and cover cropped soils. J Sustain Agr 15(2-3):19-31. https://do org/10.1300/J064v15n02_04
Pathak TB, Maskey ML, Dahlberg JA, et al. 2018. Climate change trends and impacts on California agriculture: A detailed review. Agronomy 8(3):25. https://doi. org/10.3390/agronomy8030025

Paw U KT, Qiu J, Su H-B, et al. 1995. Surface renewal analysis: A new method to obtain scalar fluxes. Agr For Meteorol 74(1):119-37. https://doi.org/ 10.1016/0168-1923(94)02182-J

Pieters AJ, McKee R. 1938. The use of cover and green-manure crops. In USDA Yearbook of Agriculture. p 431-44. Washington, DC: US Government Printing Office.

Prichard T, Sills W, Asai W, et al. 1989. Orchard water use and soil characteristics. Calif Agr 43(4):23-5. https://calag. ucanr.edu/Archive/?article=ca. v043n04p23

Rodriguez JM, Molnar JJ, Fazio RA, et al. 2009. Renew Agr Food Syst 24(1):60-71. https://doi.org/10.1017/

S1742170508002421

Sarrantonio M, Gallandt E. 2003. The role of cover crops in North American cropping systems. Crop Production 8(1-2):53-74. https://doi.org/10.1300/ J144v08n01_04
Shackelford GE, Kelsey R, Dicks LV. 2019. Effects of cover crops on multiple ecosystem services: Ten meta-analyses of data from arable farmland in California and the Mediterranean. Land Use Policy 88:104204. https:// doi.org/10.1016/j.landusepol.2019.104204

Snyder, R L, Donatella Spano, Paw U KT. 1996. Surface renewal analysis for sensible and latent heat flux density. Bound-Lay Meteorol 77:249-66. https://doi. org/10.1007/BF00123527

Soil Health Institute. 2019 Progress report: Adoption of soil health systems based on data from the 2017 U.S. Census of Agriculture. Morrisville, NC: Soil Health Institute. 22 p. https:// soilhealthinstitute.org/wpcontent/uploads/2019/07/SoilHealth-Census-Report.pdf

Tautges NE, Chiartas JL, Gaudin ACM, et al. 2019. Deep soil inventories reveal that impacts of cover crops and compost on soil carbon sequestration differ in surface and subsurface soils. Global Change Biol 25(11):3753-66. https://doi. org/10.1111/gcb.14762

Ward PR, Flower KC, Cordingley $\mathrm{N}$, et al. 2012. Soil water balance with cover crops and conservation agriculture in a Mediterranean climate. Field Crop Res 132:33-9. https://dol. org/10.1016/j.fcr.2011.10.017 